\title{
NOVEL DUA IBU KARYA ARSWENDO ATMOWILOTO : KAJIAN ANTROPOLOGI SASTRA, NILAI PENDIDIKAN KARAKTER, DAN RELEVANSINYA SEBAGAI BAHAN PENGAJARAN SASTRA DI SMA
}

\author{
Bayu Romadi, Suyitno, Edy Suryanto \\ Universitas Sebelas Maret \\ Surel: bayuromadi@gmail.com
}

\begin{abstract}
Abstrak: Teknik pengumpulan data yang digunakan dalam penelitian ini adalah dokumentasi dan wawancara mendalam dengan informan. Validitas data menggunakan triangulasi data dan triangulasi teori. Teknik analisis menggunakan model interaktif. Data utama penelitian ini diperoleh dari novel Dua Ibu karya Arswendo Atmowiloto dengan tebal 300 halaman. Novel tersebut dikaji dengan pendekatan antropologi sastra. Berdasarkan pendekatan tersebut, ditemukan bahwa: (1) kompleksitas ide yang meliputi hubungan manusia dengan alam, dengan sesama, dan hakikat hidup manusia; (2) kompleksitas aktivitas yang ada pada masyarakat Jawa dalam novel Dua Ibu; (3) kompleksitas hasil budaya berupa hasil budaya bentuk bahasa, bentuk pengetahuan, bentuk teknologi, dan bentuk mata pencaharian (4) nilai pendidikan karakter yang terdapat di dalam novel Dua Ibu; serta (5) relevansinya dengan pembelajaran sastra di SMA. Kehidupan budaya yang digambarkan pengarang didominasi oleh adat budaya Jawa yaitu Solo. Teknik analisis menggunakan model interaktif. Simpulan dari penelitian ini menunjukan bahwa unsur mitologi, filsafat, dan budaya jawa dapat dijadikan sebagai acuan kepada pendidik terutama di daerah Jawa Tengah untuk dasar sebagai pendekatan dalam menguatkan nilai karakter peserta didik maupun budi pekerti yang sesuai dengan kebudayaan jawa.
\end{abstract}

Kata kunci: novel, antropologi, nilai pendidikan karakter, relevansi pembelajaran sastra

\section{DUA IBU NOVEL BY ARSWENDO ATMOWILOTO: THE STUDY OF LITERATURE ANTROPOLOGY, CHARACTER EDUCATION VALUES, AND ITS RELEVANCE AS LEARNING MATERIAL OF LITERATURE IN SENIOR HIGH SCHOOL}

\begin{abstract}
Data collection techniques used in this study are documentation and in-depth interviews with informants. Data validity uses data triangulation and theory triangulation. Analysis techniques using interactive models. The main data of this research was obtained from the novel Dua Ibu by Arswendo Atmowiloto with a thickness of 300 pages. The novel is studied with a literary anthropological approach. Based on this approach, it was found that: (1) the complexity of ideas which included human relations with nature, with others, and the nature of human life; (2) the complexity of the activities that exist in Javanese society in the Dua Ibu novel; (3) the complexity of cultural results in the form of cultural results in the form of language, forms of knowledge, forms of technology, and forms of eye search; (4) the value of character education contained in the Dua Ibu novel; and (5) its relevance as literary learning in high school. The cultural life described by the author is dominated by Javanese cultural customs, namely Solo. Analysis techniques using interactive models. Conclusions from this study indicate that elements of mythology, philosophy, and Javanese culture can be used as a reference to educators, especially in Central Java for the basis of an approach to strengthen the value of the character of students and character that is in accordance with Javanese culture.
\end{abstract}

Keywords: novel, anthropology, character education value, relevance of literary learning 


\section{PENDAHULUAN}

Masalah pendidikan menjadi fokus utama dalam suatu bangsa. Fokus pemerintah dalam mengamalkan nilai pendidikan karakter di sekolah-sekolah tidak disertai dengan pemberian contoh yang baik oleh orang-orang berkemeja putih bahkan para pengajar yang berada di sekolah-sekolah. Kasus-kasus yang dikabarkan oleh media seperti bocornya ujian nasioanl, tindak kekerasan yang dilakukan oleh guru atau murid, kasus lain yang menjadikan pendidikan sebagai dagangan, sampai gerakan-gerakan yang mengatas namakan pendidikan dan literasi tanpa ada tujuan yang jelas kedepanya. Banyak hal yang harus kita perbaiki namun yang paling utama bahwa kita harus membenahi sekrup-sekrup yang ada pada diri sendiri dan sekitar kita terlebih dahulu, untuk kemudian membuat suatu perubahan yang melibatkan khalayak besar bukan malah sebaliknya.

Hal tersebut tampaknya terkait dengan masalah pandangan moral, pandangan tentang baik dan buruk, tentang benar dan salah, yang juga belum tentu sama di antara berbagai bangsa. Padahal, pandangan tentang moral merupakan pondasi yang penting bagi pembentukan karakter. Namun, untuk memeroleh sebutan sebagai orang berkarakter sebenarnya lebih dari sekadar bermoral karena sebutan menjadi berkarakter memiliki tuntutan dan makna yang lebih tinggi. Sampai saat ini pembelajaran hanya memfokuskan diri pada ranah kognitif untuk menghafal dan mempersipakan siswa pada ujian semata. Masih sedikit yang menrapkan bagaimana memacu peserta didik utuk berkembang mencari solusi atas permasalahan yang sedang dihadapi. Tentu saja hal tersebut berdapak pada cara berpikir untuk melakukan segala hal dengan isntan dan cepat tanpa mengetahui proses dan hanya mengutamakan hasil.

Kondisi tersebut juga mencerminkan bahwa berbagai persoalan yang muncul di dalam pendidikan yang belum kuat secara kemanusiaan akan melemahkan kepribadian bangsa. Semangat untuk belajar, berdisiplin, beretika, bekerja keras, dan sebagainya akan menurun. Peserta didik banyak yang tidak siap untuk menghadapi kehidupan sehinggadengan mudah meniru budaya luar yang negatif (Nurgiyantoro, 2014. 113).

Tindakan meniru budaya luar dilakukan bukan tanpa alasan, kurangnya pendekatan yang dilakukan untuk memperkenalkan budaya sendiri menjadi salah satu alasanya. Adanya perkembangan teknologi, media dan informasi, internet, dan sebagainya yang tidak diimanfaatkan dengan tepat bisa menyebabkan negara kita kurang berkembang. Sudah saatnya kembali ke asal tentang siapa diri kita sendiri. Menjadikan budaya asal, warisan nenek moyang sebagai pondasi dalam menghadapi perubahan zaman.

Dalam penelitian ini digunakan antropologi untuk membedah tentang apa saja nilai- nilai yang telah diwariskan oleh leluhur. Karya sastra digunakan sebagai media untuk mengenalkan dan mengajarakan nilai-nilai warisan.

$$
\text { Pada hakikatnya sastra dan }
$$
kebudayaan memiliki objek yang sama yaitu manusia dalam masyarakat, manusia sebagai fakta sosial, manusia sebagai mahkluk kultural (Ratna, 2005:14). Sastra merupakan suatu wujud dan hasil dari kebudayaan. Sastra terjadi dalam konteks sosial sebagai bagian dari kebudayaan yang menyiratkan masalah tradisi, konvensi, norma, genre, simbol, dan mitos.Sastra memiliki potensi yang besar untuk membawa masyarakat ke arah perubahan, termasuk perubahan karakter Hal itu terjadi karena sastrawan dipengaruhi dan mempengaruhi masyarakat (Wellek dan Werren, 1990:120). Kesenian itu pula merupakan bentuk budaya. Pembaca karya sastra dapat menjadikan karya sastra sebagai solusi yang dapat membantunya dalam kehidupan sehari-hari dalam kehidupan di lingkungan masyarakat. 
Di sinilah salah satu peran karya sastra khususnya novel yang di dalamnya tidak hanya memiliki fungsi menghibur, akan tetapi memilik fungsi edukatif pula. Sumardjo (1982:39), pernah menyatakan tentang adanya kebangkitan kembali kebudayaan Jawa dalam kesusastraan Indonesia. Maksudnya, karya sastra dapat dipandang sebagai sumber informasi tentang manifestasi untuk menanamkan pendidikan budaya Jawa pada generasi sekarang.Dalam berbagai kegiatan ilmiah, novel kerap menjadi topik yang dikaji secara mendalam. Di lingkungan Fakultas Pendidikan Bahasa, novel dijadikan materi perkuliahan. Dalam silabus mata pelajaran Bahasa Indonesia di SMP dan SMA novel menjadi materi pengajaran sastra.

Hal tersebut menunjukkan bahwa novel bukan hanya sebagai bahan bacaan hiburan saja, melainkan bagian dari salah satu karya sastra yang perlu dikaji dan dikembangkan (Nasution:2016. 16).Aspekaspek antropologi sastra dan nilai-nilai kebudayaan, serta pendidikan karakter dalam novel Dua Ibu karya Arswendo Atmowiloto dapat dijadikan sebagai materi ajar dalam pembelajaran sastra di SMA yang diaplikasikan dalam silabus mata pelajaran Bahasa Indonesia, sebagai bahan pembelajaran sastra di SMA. Sastra bukan hanya sebagai pewaris budaya semata sebab di dalamnya juga terkandung nilainilai pendidikan. Ragam pendidikan yang terkandung dalam karya sastra lembut menyentuh nurani pembacanya, serta tidak terdapat unsur memaksakan.

\section{METODE PENELITIAN}

Penelitian ini adalah penelitian yang bersifat kualitatif dengan objek kajian berupa karya sastra yakni novel yang berjudul Dua Ibu Karya Arswendo Atmowiloto. Penelitian ini tidak terikat dengan tempat dan waktu yang khusus. Pada penelitian ini waktu dan kegiatan penelitian bersifat fleksibel sesuai dengan karakteristik penelitian kualitatif. Jenis metode kualitatif yang digunakan pada penelitian ini deskriptif analitik yang mengkaji makna dalam Novel Dua Ibu Karya Arswendo Atmowiloto. Menurut Ratna (2010:335) metode deskriptif analitik merupakan metode dengan cara menguraikan sekaligus menganalisis dengan menggunakan kedua cara secara bersama-sama diharapkan objek dapat diberikan makna secara maksimal.

Pendekatan yang digunakan dalam penelitian ini yaitu antropologi sastra. Menurut Endraswara, (2013:1) dengan menggunakan unsur-unsur antropoetnik yang paling dominan dalam karya sastra yang diteliti, yaitu sistem bahasa, sistem pengetahuan, sistem religi dan kesenian, dan sistem mata pencarian. Selain itu, penelitian ini juga menguraikan nilainilai pendidikan karakter yang terdapat di dalam novel Dua Ibu. Aspek antropologi sastra dan nilai pendidikan karakter, dapat diketahui relevansi keduanya dengan pembelajaran sastra di Sekolah Menengah Atas (SMA).

Sumber data primer dalam penelitian ini adalah novel Dua Ibu karya Arswendo Atmowiloto yang diterbitkan oleh Gramedia Pustaka Utama tahun 2017, cetakan kedua. Sumber data sekunder dapat diperoleh melalui data-data yang bersumber dari buku-buku acuan yang berhubungan dengan permasalahan yang menjadi objek penelitian. Penelitian ini menggunakan triangulasi metode, triangulasi teori, dan triangulasi sumber. Triangulasi metode adalah pemeriksaan keabsahan data hasil analisis dengan menggunakan beberapa teknik pengumpulan data yang berbeda. Walaupun triangulasi teori adalah pemeriksaan kebenaran data hasil analisis dengan menggunakan teori yang berbeda tetapi membahas masalah yang sama. Data yang telah berhasil digali, dikumpulkan, dan dicatat dalam kegiatan penelitian harus diusahakan kemantapan dan kebenarannya.

Sutopo, (2002: 78) menyebutkan empat macam triangulasi yakni (1) triangulasi data, (2) triangulasi peneliti, (3) triangulasi metode, dan (4)triangulasi teori. 
Teknik trianggulasi data atau sumber berarti membandingkan dan mengecek balik derajad kepercayaan suatu informasi dari narasumber satu dengan lainnya dan yang diperoleh melalui catatan atau arsip serta dokumen yang memuat catatan yang berkaitan dengan data yang dimaksudkan peneliti.

\section{HASIL DAN PEMBAHASAAN Kompleksitas Ide}

Ide tentang hakikat hidup manusia yang terdapat dalam Novel Dua Ibu adalah sikap nerima berarti merasa puas dengan nasib dan kewajiban yang telah ada, tidak memberontak, tetapi mengucapkan terima kasih. Sabar, menunjukkan ketiadaan ketidaksabaran, ketiadaan nafsu yang bergolak.

Menurut Jong (dalam Astutik, 2012:3), tentang sikap hidup masyarakat Jawa dinyatakan bahwa masyarakat Jawa memiliki sikap hidup rila, nrima, dan sabar. Pandangan selanjutnya tampak adanya hakikat hidup manusia adalah buruk atau penuh dan tidak terlepas dari masalah sehingga manusia dapat mengusahakan untuk menjadikannya suatu hal yang baik dan juga menggembirakan.

Pandangan hakikat hidup orang Jawa yakni mengenalnya kepasrahan dan keikhlasan dalam menjalani kehidupan serta di sisi lain juga ada usaha untuk memperbaiki keadaan dengan usaha keras dan pengorbanan. Melalui keuletan ibunya yang digambarkan sebagai tokoh $\mathrm{Bu}$ Marsono (Ibu) menjadi bentuk nyata adanya usaha dan ikhtiarnya dalam menjalani kehidupan agar lebih baik lagi kedepannya.

Terdapat dua hakikat kedudukan manusia dalam ruang dan waktu yang tampak pada cerita novel tersebut, yaitu pandangan tentang masa lalu sebagai pembelajaran masa sekarang dan pandangan masa lalu terhadap orientasi masa depan. Hal ini mengindikasikan bagaimana pandangan umum manusia atau masyarakat dalam menentukan tindakan yang akan dilakukan. Melalui tokoh dalam novel tersebut diketahui masyarakat Jawa, menggunakan orientasi waktu ke masa lalu, masa sekarang, dan masa depan. Hal itulah yang tergambar dari pemikiran dan pertimbangannya dalam melakukan pekerjaan dan mengambil keputusan untuk hidupnya.

Masa lalu sebagai pegangan supaya berhati-hati mengambil keputusan, dan orientasi ke masa depan sebagai upaya merencanakan kehidupan yang lebih baik.Mengenai hakikat manusia dengan alam Idrus (2007: 394) mengemukakan bahwa penghargaan masyarakat tentang alam ada dua pandangan. Berdasarkan hasil kajian, tampak adanya data yang mengindikasikan bahwa manusia itu adalah penguasa alam. Dan menjadikan alam sebagai wahana untuk hidup. Hal tersebut tampak adanya kecenderungan yang muncul dari tokoh Solemah yang menanam pohon pepaya sebagai sumber makanan.

Pandangan bahwa alam memiliki kekuatan yang tidak terduga, dialami oleh tokoh Jamil ketika merantau. Jamil saat itu terjebak bencana alam banjir yang memaksanya harus berlindung satu harisatu malam di atas pohon jambu untuk bertahan hidup.Berdasarkan hasil pengkajian data pada Novel Dua Ibu mengenai hubungan manusia dengan sesamanya ditemukan dua orientasi hubungan, yaitu secara vertikal dan horizontal.

Orientasi hubungan secara vertikal yang memunculkan adanya sikap kepatuhan terhadap orang yang lebih tua ditemukan pada tokoh anak-anak keluarga Marsono. Dalam surat yaang dituliskan Solemah kepada ibunya, selalu dituliskan kata-kata "sungkem pangabekti" yang bertujuan untuk menunjukkan bakti anak kepada orang tuanya. Orientasi hubungan antara sesama secara horizontal pada Novel Dua Ibu tampak pada tindakan Ratsih yang mau mengantarkan Mamid berobat ketika sakit. 


\section{Kompleksitas Aktivitas}

Berdasarkan temuan data, terdapat kompleksitas aktivitas tokoh dalam bidang kekerabatan, yakni meliputi aktivitas kekerabatan berupa pernikahan, aktivitas kekerabatan berupa tolong menolong kerabat, aktivitas kekerabatan berupa pengasuhan anak-anak, dan aktivitas kekerabatan berupa menjaga hubungan baik pergaulan antarkerabat.

Temuan data tersebut menunjukkan pandangan masyarakat Jawa tentang pentingnya makna kekerabatan dalam kehidupan. J.L. Gillin dan J.P. Gillin (dalam Koentjaraningrat, 2009: 166) menyatakan bahwa pranata yang berfungsi untuk memenuhi keperluan kekerabatan, yaitu yang sering disebut domestic institutions. Bentuk sikap menolong yang dilakukan $\mathrm{Bu}$ Martono untuk mengasuh anak Pakdhe Wiro adalah salah satu contoh hubungan kekerabatan yang ada dalam Novel Dua Ibu. Bentuk lain yaitu ketika Pak Martono memberikan sabagian uang gaji kepada saudaranya untuk membantu keperluan hidup. Aktivitas di bidang ekonomi bertujuan untuk memperoleh atau menghasilkan pendapatan atau uang yang digunakan untuk memenuhi kebutuhan hidup.

Berdasarkan hasil penelitan pada Novel Dua Ibu, ditemukan sejumlah data yang menunjukkan beragam mata pencaharian yang dimiliki para tokoh dalam novel tersebut, di antaranya pedagang, abdi dalem Kraton, tentara, pegawai televisi, dan pengumpul rambut bekas.Pada Novel Dua Ibu aktivitas rekreasi lebih banyak ditemukan dibandingkan dengan kesenian.

Rekreasi yang disebutkan antara lain adalah pasar malam sekaten, Taman Sriwedari, yaitu taman yang dibangun oleh Pakubuwana X. Di dalam Taman Sriwedari terdapat pagelaran kesenian wayang orang yang digelar setiap hari selasa sampai minggu. Terdapat pula wahana rekreasi untuk anak dan pedagang yang menjajakan beraneka ragam dagangan.
Aktivitas sistem kepercayaan dan religi ditemukan pada saat Mamid dikhitankan. Secara tradisi anak yang akan berangkat khitan, harus terlebih dahulu digendong oleh orang tuanya. Hal tersebut dimaksudkan agar orang tua si anak yang menanggung beban sakit anak yang dikhitankan. Aktivitas lain antaralain adalah pernikahan dengan adat Jawa, upacara pemakaman dan setelah pemakaman, serta Grebeg Sekaten. Koentjaraningrat (1979: 343) menyatakan bahwa kegiatan adat istiadat orang Jawa yang terpenting adalah upacara, di dalamnya terdapat prosesi tahapan prosesi pelaksanaan yang serat makan.

Hasil penelitian Novel Dua Ibu mengenai aktivitas tokoh di bidang pendidikan ditemukan bahwa pendidikan yang diperoleh beberapa tokoh di dapatkan hanya melalui institusi formal. Data yang ada menunjukkan bahwa sekolah yang dibuat oleh istitusi menjadi sumber pendidikan tokoh. Para kaum priyayi di kota memang miliki peluang lebih besar untuk bisa menyekolahkan anaknya sampai tingkah perguruan tinggi. Dalam Koentjaraningrat (1979: 284) menyatakan bahwa para priyayi yang memiliki gelar kesarjanaan banyak yang berasal dari kota. Dapat disimpulkan aktivitas pendidikan dalam Novel Dua Ibu lebih pada bentuk sekolah formal, yaitu sekolah AMS (Algemeen Metddelbere School) oleh Pak Marsono, SD dan SMP oleh Jamil, Mamid dan Ratsih.

\section{Kompleksitas Hasil Budaya}

Hasil temuan budaya berbentuk bahasa dalam Novel Dua Ibu kebanyakan menggunakan istilah panggilan bahasa Jawa untuk menyebut orang yang lebih tua atau dalam berkomunikasi dengan sesama. Sebutan untuk seorang yang lebih tua seperti, mbakyu pakdhe, budhe, mbah. Mbakyu adalah sebutan untuk kakak perempuan dalam bahasa Jawa. Pakdhe yang merupakan akronim dari bapak gedhe, adalah sebutan untuk kakak lakilaki dari orang tua. Budhe merupakan 
akronim dari ibu gedhe, sebutan untuk kakak permepuan dari orang tua, dan mbah yaitu sebutan untuk orang tua dari ayah atau ibu. Novel Dua Ibu menunjukkan adanya budaya sopan santun dalam berbahasa yang mengandung tingkatan dalam masyarakat yang harus memperhatikan dengan siapa komunikasi berlangsung. Selain itu, juga adanya budaya menyingkat nama panggilan untuk mempermudah pengucapan dalam kehidupan sehari-hari dan penggunaan istilah untuk menyindir hal-hal tertentu.

Hasil budaya sistem pengetahuan yang terdapat dalam Novel Dua Ibu yaitu sistem pengetahuan tentang alam, biasanya digunakan untuk bercocok tanam maupun mengolahnya dalam bentuk yang lain. Tentang cara bercocok tanam terdapat pada tokoh Untung yang menanam pohon nangka, tokoh Solemah menanam pepaya, dan tokoh Ratsih dengan menanam cabe dan tomat. Pengetahuan tentang dongeng sejarah terdapat pada tokoh $\mathrm{Bu}$ Marsono yang menceritakan tentang silsilah keluarga Kraton Demak.

Pengetahuan dalam mengolah bahan makanan yaitu dengan memasak bestik dan pecel. Hasil budaya bentuk teknologi yang terdapat dalam Novel Dua Ibu antaralain adalah mobil VW, radio, andong, kereta api, mesin jahit, televisi, wesel, dan tikar. Masyarakat Jawa memiliki keterbukaan dan keluwesan dalam menerima berbagai bentuk budaya dari luar, termasuk bentuk teknologinya.

Keterbukaan masyarakat Jawa dengan kebudayaan asing menurut Koentjaraningrat disebabkan adanya toleransi budaya. Sikap toleransi dan simpati terhadap kebudayaan lain menjadi faktor penentu proses asimilasi pada umumnya (2009: 256).

Dengan muculnya sikap tersebut, dalam Novel Dua Ibu, penggunaan alat hasil teknologi Eropa menjadi faktor pendorong asimilasi budaya Jawa dengan Eropa.Dalam Novel Dua Ibu terdapat berbagai macam pekerjaan yang digeluti oleh tokoh-tokohnya antaralain, pekerjaan sebagai seorang abdi dalem Keraton Surakarta. Pekerjaan tersebut dilakukan oleh Pak Marsono. Pekerjaan sebagai seorang pegawai televisi dilakukan oleh tokoh Bong. Oom Bong bekerja sebagai pengelola televisi negara pada masa itu atau TVRI yang berada di Jakarta. Pekerjaan sebagai seorang tentara dilakukan oleh John dan Untung Subarkah. Adapun pekerjaan lain yang disebutkan dalam novel seperti tukang becak, kusir andong, pedagang, dokter, guru, dan tukang pengumpul rambut bekas.

\section{Nilai Pendidikan Karakter}

Terdapat nilai pendidikan karakter dalam Novel Dua Ibu karya Arswendo Atmowiloto antara lain adalah nilai religius. Pada Novel Dua Ibu ini nilai religius digambarkan oleh pengarang melalui sikap dan keyakinan tokoh akan kekuasaan Tuhan. Nilai religius tampak pada toko $\mathrm{Bu}$ Marsono ketika mengikhlaskan kematian Pak Marsono. Nilai sikap disiplin ditunjukkan oleh tokoh Ratsih yang selalu datang lebih pagi ketika sekolah. Nilai kerja keras membuktikan bahwa segala macam halangan dalam kehidupan dapat diatasi bahkan mencapai hasil yang diharapkan walupun tidak mudah. Hal tersebut ditunjukan tokoh Murjanah dan Adam dengan bekerja dan menabung untuk membantu keluaraga.

Nilai karakter kreatif ditunjukan oleh Ratsih ketika membuat odol yang berbahan dasar arang. Caranya adalah dengan menumbuk halus arang hitam kemudian digunakan untuk mengosok gigi sebagai pengganti odol. Nilai cinta damai ditunjukkan oleh tokoh Mamid yang tidak membalas ketika dikroyok oleh temantemnya di sekolah, Mamid justru bersikap baik dan sopan pada mereka. Penghargaan yang diberikan oleh masyarakat kepada $\mathrm{Bu}$ Marsono sebagai seorang juru masak handal adalah suatu bentuk nilai menghargai prestasi.

Sikap semangat kebangsaan terlihat oleh tokoh Jon yang tetap menjalankan tugas sebagai seorang tentara angkatan 
laut. Jon harus meninggalkan keluarganya ketika ditugaskan untuk mengamankan Irian Barat. Jon menunaikan kewajibanya sebagai seorang tentara untuk melindungi NKRI dengan menempatkan kepentingan negara di atas keluarga. .

Sikap peduli sosial $\mathrm{Bu}$ Marsono adalah dengan membantu sebagai juru masak ketika ada upacara adat istiadat. Sikap yang demikian juga ditunjukkan oleh Pak Marsono, yaitu dengan memberikan sebagaian gajinya kepada saudara yang membutuhkan. Sikap tanggung jawab juga tunjukkan oleh $\mathrm{Bu}$ Marsono, yaitu dengan menikahkan dan megkhitankan anak-anak asuhnya, selain itu $\mathrm{Bu}$ Marsono juga membayar hutanghutangnya. Sikap tanggung jawab yang demikian $\mathrm{Bu}$ Marsono selalu mudah mendapatkan pinjaman kepada siapa saja.

\section{Relevansi sebagai Bahan Pengajaran Sastra di SMA}

Novel Dua Ibu karya Arswendo Atmowiloto jika dikaitkan dengan materi pembelajaran bahasa Indonesia pada kelas XII Sekolah Menengah Atas (SMA) semester ganjil dengan standar kompetensi (SK) memahami pembacaan novel dengan kompetensi dasar (KD), yaitu menanggapi pembacaan penggalan novel dari segi vokal, intonasi, dan penghayatan. Berdasarkan pendapat Rahmanto (1988:

29) dalam memilih bahan pengajaran sastra hendaknya dihadirkan sesuatu yang erat hubungannya dengan latar belakang budaya dan materi tetang budaya lokal tidak boleh terlupakan karena hal tersebut merupakan akar budaya bangsa.

Novel Dua Ibu mengambil banyak menggunakan kebudayaan Jawa lebih dekat dengan lingkungan hidup siswa yang berdarah Jawa. Penggunaan bahasa Indonesia dan latar cerita dalam Novel Dua Ibu dapat diterima semua kalangan. Menurut wawancara dengan $\mathrm{Bu}$ Asqina, Novel Dua Ibu menggunakan sudut pandang anak kecil dalam penyampaian cerita. Hal tersebut membuat pembaca tertarik mengikuti kisah dari lembar ke lembar selanjutnya.

Kisah keluguan yang diceritakan dari sudut pandang anak kecil dapat menjadi poin tambahan ketika menggunakan Novel Dua Ibu sebagai materi pengajaran sastra. Penggunaan bahasa Indonesia dan pemilihan gaya bahasa yang bagus juga menjadi pertimbangan novel tersebut untuk dijadikan sebagai materi pengajaran, karena mudah dipahami. Perilaku yang ditunjukan oleh tokoh dalam Novel Dua Ibu mampu memberikan dampak kepada siswa tidak hanya tentang bagaimana berperilaku yang baik saat di sekolah tetapi juga menhormati juga menyayangi orang tua dan saudara di rumah.

\section{SIMPULAN}

Berdasarkan analisis yang dilakukan dengan kajian antropologi terdapat data kompleksitas ide yaitu hakikat hidup manusia, pandangan terhadap ruang dan waktu, hubungan manusia dengan alam, dan hubungan manusia dengan sesama dari tokoh utama $\mathrm{Bu}$ Marsono maupun tokoh lain. Kompleksitas aktivitas berupa bidang ekonomi, bidang kekrabatan, bidang pendidikan, sistem kepercayaan, bidang rekreasi yang dilakukan oleh tokoh dalam Novel Dua Ibu. Hasil temuan data berupa kompleksitas hasil budaya yang meliputi, bentuk bahasa yaitu bahasa Jawa. Bentuk teknologi berupa andong, becak, mobil, televisi, kereta api. Bentuk pengetahuan tentang sejarah, pengetahuan membuat makanan, pengetahuan membuat alat-alat dengan bahan yang ada dialam, pengetahuan cara bercocok tanam.

Hasil budaya bentuk pekerjaan meliputi, abdi dalem, tentara, pegawai, pedagang, tukang becak, kusir andong. Nilai pendidikan karakter berupa religius, cinta damai, peduli sosial, semangat kebangsaan, kreatif, tanggung jawab, menghargai prestasi, disiplin, kerja keras yang terdapat dalam novel mampu memberikan pembelajaran kepada pembaca tentang kehidupan sehari-hari. 
Novel Dua Ibu memenuhi syarat sebagai materi ajar yang baik untuk siswa berdasarkan aspek kebahasaan, psikologi untuk siswa, dan latar belakang budaya, sehingga layak digunakan sebagai materi pembelajaran di SMA. Berdasarkan hasil penelitian ini diharapkan guru lebih selektif untuk memilih karya sastra yang lebih sesuai dengan siswa yang diajar. Materi yang sesuai menunjang keberhasilan dalam suatu pembelajaran, sehingga nilai-nilai positif dapat tersampaikan. (5) Dalam pembelajaran sastra yang berorientasi pada siswa tersebut, siswa dalam belajar diberi kebebasan bergerak untuk mengembangkan kepribadianya sesuai dengan perkembangan emosional mereka. Pembelajaran yang berpusat atau berorientasi pada siswa ini dalam

\section{REFERENSI}

Astuti, I. D (2012). Budaya Jawa dalam Novel Tirai Menurun Karya N.H Dini, Kajian Antropolgi Sastra. Jurnal Sastra Indonesia Fakultas Bahasa Dan Seni Universitas Negeri Surabaya.

Atmowiloto, A. (2017). Dua Ibu. Jakarta: PT Gramedia Pustaka Utama.

Depdiknas .(2003). Undang-undang RI No.20 tahun 2003 tentang Sistem Pendidikan Nasional. Depdiknas, 2006. Permen Nomor 22 Tahun 2006. Jakarta: Depdiknas.

Endraswara, S. (2013). Metodologi Penelitian Antropologi Sastra. Yogyakarta: Penerbit ombak.

Idrus, M. (2007). Makna Agama dan Budaya bagi Orang Jawa. Jurnal Universitas Islam Indonesia Yogyakarta.

Koentjaraningrat. (1979). Metode-Metode Penelitian Masyarakat. Jakarta: PT Gramedia Pustaka Utama.

Koentjaraningrat. (2009). Pengantar Ilmu Antropologi. Jakarta: PT Rineka Cipta. prosesnya harus berpedoman pada keinginan, gagasan, dan juga kreativitas peserta didik (tut wuri handayani). Dengan demikian, peserta didik akan merasa senang dan dapat menikmati pembelajaran sastra yang disampaikan oleh guru. (6) Pembelajaran pendidikan karakter lewan mata pelajaran Bahasa Indonesia, khususnya pembelajaran sastra remaja di SMA, sebagaimana halnya dengan matamata pelajaran yang lain, perlu adanya penentuan prioritas-prioritas pada nilainilai karakter tertentu. Hal itu dimakudkan agar guru dan peserta didik dapat lebih memfokus pada sejumlah nilai dan lebih memudahkan pemantauan, pengawasan, dan penilaiannya. Namun, hal itu tidak perlu diartikan abai terhadap nilai-nilai karakter yang lain yang tidak menjadi fokus

Nurgiyantoro, B (2014). Sastra Anak dan Pembentukan Karakter. Jurnal Cakrawala Pendidikan. Universitas Negeri Yogyakarta: Yogyakarta

Nurgiyantoro, B dan Efendi, A. (2013). Prioritas Pembentukan Nilai Pendidikan Karakter dalam Pembelajaran Sastra Remaja. Jurnal Cakarawala Pendidikan, 32(3).

Ratna, N. K. (2005). Sastra dan Cultural Studies Representasi Fiksi dan Fakta. Yogyakarta: Pustaka Pelajar Sumardjo, Y. (1982). Masayarakat dan Sastra Indonesia. Yogyakarta: Nur Cahaya.

Sutopo, H.B. (2002). Metodologi Penelitian Kulaitatif. Surakarta: UNS Press.

Wellek, R dan Austin Werren. (1990). Teori Kesusastraan. (Terjemahan Melani Budianti). Jakarta: Garamedia. 